\title{
Could single nucleotide polymorphisms influence on the efficacy of platelet-rich plasma in the treatment of sport injuries?
}

\author{
Ricard Pruna ${ }^{1}$ \\ Lluis Til ${ }^{1,2}$ \\ Rosa Artells ${ }^{3}$ \\ 1 Football Club Barcelona Medical Services, Barce- \\ Iona, Spain \\ 2 Olympic Center of Sports Medicine (CAR), Sant Cu- \\ gat del Vallés, Barcelona, Spain \\ 3 SM Genomics, Barcelona Science Park, Barcelona, \\ Spain
}

\author{
Corresponding Author: \\ Rosa Artells \\ SM Genomics \\ Helix Building Barcelona Science Park \\ Baldiri Reixac 15-21, Lab02A5bis \\ 08028 Barcelona, Spain \\ E-mail:rosa@smgenomics.com
}

\section{Summary}

Platelet-rich plasma (PRP) is a new powerful biological tool in sports medicine, when used to treat tendon, ligament and muscle injuries. PRP is a fraction of autologous whole blood containing an increased number of platelets and a wide variety of cytokines that can improve and accelerate the healing of various tissues.

An analysis of the literature shows promising preclinical results for PRP treatment, but there is a lack of solid clinical proof to support its use in sports medicine, and in fact, clinical findings on individual responses to PRP treatment are contradictory. These contradictions may be due to interindividual differences in the presence of single nucleotide polymorphisms (SNPs) in genes related to PRPs and/or their receptors. These SNPs can determine a greater or lesser response to this treatment and consequently a shorter or longer recovery time.

We have focused our attention in the study of genes related to PRP with the aim to develope a genetic profile that will identify the individuals and injuries most likely to benefit from PRP treatment.

KEY WORDS: musculoskeletal soft-tissue injuries, single nucleotide polymorphisms, platelet-enriched proteins, growth factors.

\section{Introduction}

Since PRP was first introduced as topical adjuvant therapy to treat chronic leg ulcers in the late $1980 \mathrm{~s}^{1}$, its use has been extended to many fields of medicine, such as dermatology, ophthalmology ${ }^{2}$, dentistry $^{3}$ and maxillofacial surgery ${ }^{3}$. Recently, PRP injections have emerged as a fashionable non-invasive treatment also in sports medicine ${ }^{4}$, where they are used to treat acute or chronic tendinopathy ${ }^{5-8}$ and muscle $e^{9,10}$ and ligament ${ }^{11,12}$ injuries, because PRP provides numerous growth factors needed to promote the healing process. Despite the wide use of PRP injections, research into their clinical efficiency is still in its beginings, and an analysis of the literature reveals a lack of solid evidence supporting the use of $\mathrm{PRP}^{13}$. More studies are required to confirm preliminary results and provide stronger scientific evidence.

Tissue repair in musculoskeletical injuries is often a slow and sometimes incomplete process. Musculoskeletical injuries have a great impact on athletes especially elite athletes - and a rapid recovery of full efficiency and return to competition is of primary importance ${ }^{14}$. The search for a minimally invasive treatment of these injuries is of great importance, especially in the world of sports.

The use of growth factors is thought to be useful in clinical practice ${ }^{15}$ because it promotes rapid healing with a high-quality tissue and allows an early and safe return to unrestricted activity. Platelet-rich plasma $(P R P)$ is a simple and minimally invasive way to obtain a natural concentration of autologous growth factors, including IGF, EGF, TGFb1, FGF2 ${ }^{16}$, as growth factors are critical for wound healing. PRP is currently being widely experimented in different fields of medicine due to its ability to help the regeneration of tissue with low healing potential. The analysis of the literature ${ }^{17,18}$ shows promising preclinical results but contradictory clinical findings in individual response to treatment in sports injuries. These contradictions may be due to interindividual differences in the presence of single nucleotide polymorphisms (SNPs) in genes related to PRP and/or their receptors and that these SNPs can determine a greater or lesser response to treatment and consequently a shorter or longer recovery time. A SNP is a DNA sequence variation which occurs when a single nucleotide in the genome differs in similar chromosomes in a given individual. SNPs in genes related to the biology of muscles ${ }^{19,20}$, tendons $^{21-23}$ and ligaments ${ }^{24}$ have been associated with injury recovery time 25,26 . 


\section{Questions about PRPs and hypothesis}

In recent years there has been an increasing research into genes related to the healing of soft tissue $^{27}$. SNPs in genes that codify for these growth factors could influence treatment effectiveness and explain differences observed in recovery times. It is important to examine the maximum possible number of SNPs in PRP-related genes in order to identify a gene signature that promotes tissue healing in order to determine an objective measurement of an individual's predisposition to recovery after this kind of treatment. Moreover it is important to know if the presence of these SNPs correlates with a greater or lesser degree of injury repair capability and/or with a short or long recovery time and, finally to identify a genetic profile for the selection of individuals who will respond more quickly to treatment following musculoskeletal soft tissue injuries and to identify the type of injury (muscle, tendon or ligament) in which PRP treatment is most effective.

\section{Why analyze PRPs?}

Cytokines and growth factors are soluble signaling proteins affecting the process of normal wound healing $^{28}$. Cytokines control the inflammatory phase that clears cellular and extracellular matrix debris. The inflammatory stage is guided by inflammatory cells that release multiple cytokines, including IL-1. Cytokines induce expression of fibroblasts and endothelial cells and cause macrophage expression of more cytokines. As inflammation reduces, wound repair takes place ${ }^{29}$. Early wound repair includes three simultaneous steps (epithelization, neoangiogenesis and prematrix formation) and is controlled by growth factors (platelet-derived growth factor [PDGF], keratinocyte growth factor, and transforming growth factor $\beta$ ). Finally, during the later wound repair, TGFb up regulates MMPs inhibitors to help matrix construction by driving collagen expression.

Due to the high implication of these molecules in this important process, we think it is important to analyze the presence of SNPs in all of these factors to elucidate if these polymorphisms could affect the final protein function.

The most commonly studied platelet proteins include platelet-derived growth factor (PDGF), transforming growth factor (TGF- $\beta$ ), platelet-derived epidermal growth factor (PDEGF), vascular endothelial growth factor (VEGF), insulin-like growth factor 1 (IGF-1), fibroblastic growth factor (FGF), epidermal growth factor $(\mathrm{EGF})^{30}$ (Tab. 1).

\section{Future Goals}

The use of PRP treatment has increased in a somewhat random manner without real knowledge of its effectiveness, since contradictory results have been re-
Table 1. Growth factors and their associated role.

\begin{tabular}{ll}
\hline GROWTH FACTOR & POSSIBLE ROLE \\
\hline PDGF & $\begin{array}{l}\text { Angiogenesis } \\
\text { Collagen synthesis }\end{array}$ \\
\hline TGFB & Collagen type I synthesis \\
& Fibronectin synthesis \\
& Fibroblasts proliferations \\
\hline PDEGF & Cellular proliferation and \\
& differentiation \\
\hline VEGF & Vascularization \\
\hline IGF-1 & Stimulates protein \\
& synthesis \\
\hline
\end{tabular}

ported. The study of these SNPs may shed light on the tendency of certain individuals to recover more rapidly and more completely from injuries and may help identify individuals with an enhanced injury repair system.

Now our research group is investigating this issue with a group of professional football players from the Spanish League with promising results and shortly we will be able to increase our sample size with players from European teams.

Future findings will provide a tool to identify the individuals and injuries most likely to benefit from PRP treatment and thus improve not only recovery time but also restitutio ad integrum by reducing the risk of re-injury and scars production.

The study meets the ethical standards of the Journal ${ }^{31}$.

\section{Acknowledgements}

Many thanks are given to Prof. Nicola Maffulli for the help given in preparing the present manuscript and to Manel Garcia from FC Barcelona Medical Services.

\section{References}

1. Knighton DR, Doucette M, Fiegel VD, Ciresi K, Butler E, Austin $L$. The use of platelet derived wound healing formula in human clinical trials. Prog Clin Biol Res. 1988;266:319-329.

2. Paques $M$, Chastang $C$, Mathis $A$, et al. Effect of autologous platelet concentrate in surgery for idiopathic macular hole: results of a multicenter, double-masked, randomized trial. Platelets in Macular Hole Surgery Group. Opthtalmology. 1999; 106:932-938.

3. Oprea WE, Karp JM, Hosseini MM, Davies JE. Effect of platelet releasate on bone cell migration and recruitment in vitro. J Craniofac Surg. 2003;14:292-300.

4. Creaney L, Hamilton B. Growth factor delivery methods in the management of sports injuries: the state of play. $\mathrm{Br} \mathrm{J}$ Sports Med. 2008;42:314-320.

5. Chen CH, Cao Y, Wu YF, Bais AJ, Gao JS, Tanq JB. Tendon healing in vivo: gene expression and production of multiple growth factors in early tendon healing period. J Hand Surg Am. 2008;33:1834-1842.

6. de Vos RJ, Weir A, van Schie HT, Bierma-Zeinstra SM, Verhaar JA, et al. Platelet-rich plasma injection for chronic Achilles 
tendinopathy: a randomized controlled trial. JAMA. 2010;13 (303):144-149.

7. Kajikawa $\mathrm{Y}$, Morihara $\mathrm{T}$, Sakamoto $\mathrm{H}$, et al. Platelet-rich plasma enhances the initial mobilization of circulation-derived cells for tendon healing. J Cell Physiol. 2008;215:837-845.

8. Kobayashi $\mathrm{M}$, Itoi $\mathrm{E}$, Minagawa $\mathrm{H}$, et al. Expression of growth factors in the early phase of supraspinatus tendon healing in rabbits. J Shoulder Elbow Surg. 2006;15:371-377.

9. Wright-Carpenter T, Opolon $\mathrm{P}$, Appell HJ, Meijer H, Wehling $\mathrm{P}$ Mir LM. Treatment of muscle injuries by local administration of autologous conditioned serum: animal experiments using a muscle contusion model. Int J Sports Med. 2004; 25(8):582587.

10. Foster TE, Puskas BL, Mandelbaum BR, Gerhardt MB, Rodeo SA. Platelet-rich plasma: from basic science to clinical applications. Am J Sports Med. 2009;37:2259-2272.

11. Radice F, Yánez R, Gutiérrez V, Rosales J, Pinedo M, Coda $\mathrm{S}$. Comparison of magnetic resonance imaging findings in anterior cruciate ligament grafts with and without autologous platelet-derived growth factors. Arthroscopy. 2010,26:5057.

12. Molloy T, Wang $Y$, Murrell $G$. The roles of growth factors in tendon and ligament healing. Sports Med. 2003;33:381-394.

13. Kon E, Filardo G, Di Martino A, Marcacci M. Platelet-rich plasma (PRP) to treat sports injuries: evidence to support its use Knee Surg. Sports Traumatol Arthrosc. 2010;19(4):516-527.

14. Ekstrand J, Hägglund $M$, Waldén $M$. Injury incidence and injury patterns in professional football: the UEFA injury study. $\mathrm{Br}$ J Sports Med. 2009;45(7):553-558.

15. Alsousou J, Ali A, Willett K, Harrison P. The role of platelet-rich plasma in tissue regeneration. Platelets. 2013;24(3):173-182.

16. Mazzocca AD, McCarthy MB, Chowaniec DM, Dugdale EM, Hansen D, Cote MP, Bradley JP et al. The Positive Effects of Different Platelet-Rich Plasma Methods on Human Muscle, Bone, and Tendon cells. Am J Sports Med. 2012;40:17421749.

17. Stanco D, Vigano' M, Croiset SJ, De Girolamo L. Applications and limits of platelet-rich plasma in sports related injuries. J Biol Regul Homeost Agents. 2012; 26(2 Suppl 1):53S-61S.

18. Kon E, Filardo G, Di Martino A, Marcacci M. Platelet-rich plasma (PRP) to treat sports injuries: evidence to support its use. Knee Surg Sports Traumatol Arthrosc. 2011;19(4):516-527.

19. Cupeiro R, Benito PJ, Maffulli N, Calderón FJ, GonzálezLamuño D. MCT1 genetic polymorphism influence in high in- tensity circuit training: a pilot study. J Sci Med Sport. 2010 13:526-530.

20. Harmon BT, Orkunoglu-Suer EF, Adham K, et al. CCL2 and CCR2 variants are associated with skeletal muscle strength and change in strength with resistance training. J Appl Physiol. 2010;109(6):1779-1785.

21. Magra M, Maffulli N. Genetics: does it play a role in tendinopathy? Clin J Sport Med. 2007;17:231-233.

22. Mokone GG, Gajjar M, September AV, Schwellnus MP, Greenberg J, Noakes TD, Collins M. The guanine-thymine dinucleotide repeat polymorphism within the tenascin-C gene is associated with achilles tendon injuries. Am J Sports Med. 2005;33:1016-1021.

23. September AV, Schwellnus MP, Collins M. Tendon and ligament injuries: the genetic component. Br J Sports Med. 2007;41:241-246.

24. Posthumus M, September AV, O'Cuinneagain D, van der Merwe W, Schwellnus MP, Collins M. The COL5A1 gene is associated with increased risk of anterior cruciate ligament ruptures in female participants. Am J Sports Med. 2009;37:2234-2240.

25. Yamin C, Duarte J, Oliveira J, Amir O, Sagiv M, Eynon N, Amir RE. IL6 (-174) and TNFA (-308) promoter polymorphisms are associated with systemic creatine kinase response to eccentric exercise. Eur J Appl Physiol. 2008;104:579-586.

26. Paulin D, Huet A, Khanamyrian L, Xue Z. Desminopathies in muscle disease. J Pathol. 2004,204:418-427.

27. Pruna R, Artells R, Ribas J, Montoro B, Cos F, Muñoz C, Rodas $G$, et al. Single nucleotide polymorphisms associated with non-contact soft tissue injuries in elite professional soccer players: influence on degree of injury and recovery time. BMC Musculoskelet Disord. 2013;14:221. doi: 10.1186/1471-247414-221.

28. Goldman R. Growth factors and chronic wound healing: Past, Present and Future. Adv Skin Wound Care. 2004;17:24-35.

29. Fahey TJ, Sherry B, van Deventer S, Jones WG, Minei JP, Morgello S, et al. Cytokine production in a model of wound healing: the appearance of MIP-1, MIP-2, cachectin/TNF and IL-1. Cytokine. 1990;2:92-99.

30. Engebretsen L, Steffen K, Alsousou J, et al. IOC consensus paper on the use of platelet-rich plasma in sports medicine. $\mathrm{Br}$ J Sports Med. 2010;44:1072-1081.

31. Padulo J, Oliva F, Frizziero A, Maffulli N. Muscle, Ligaments and Tendons Journal-Basic principles and recommendations in clinical and field science. MLTJ. 2013; 4:250-252. 